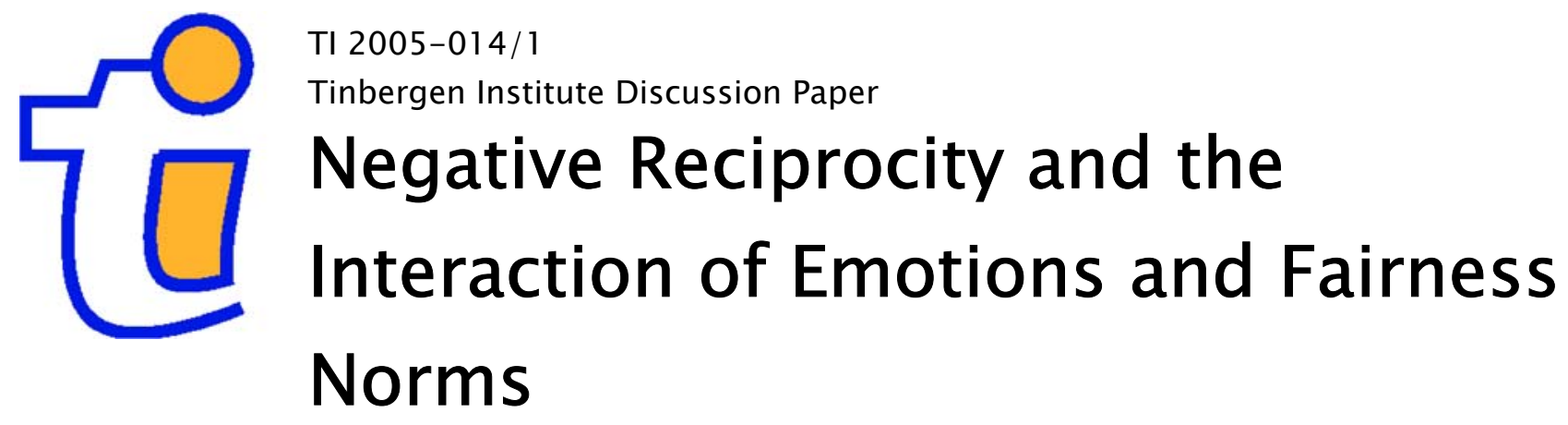

Ernesto Reuben

Frans van Winden

CREED, Department of EConomics, Universiteit van Amsterdam, and Tinbergen Institute. 
Tinbergen Institute

The Tinbergen Institute is the institute for economic research of the Erasmus Universiteit Rotterdam, Universiteit van Amsterdam, and Vrije Universiteit Amsterdam.

Tinbergen Institute Amsterdam

Roetersstraat 31

1018 WB Amsterdam

The Netherlands

Tel.: $\quad+31(0) 205513500$

Fax: $\quad+31(0) 205513555$

Tinbergen Institute Rotterdam

Burg. Oudlaan 50

3062 PA Amsterdam

The Netherlands

Tel.: $\quad+31(0) 104088900$

Fax: $\quad+31(0) 104089031$

Please send questions and/or remarks of nonscientific nature to driessen@tinbergen.nl.

Most TI discussion papers can be downloaded at http://www.tinbergen.nl. 


\title{
NEGATIVE RECIPROCITY AND THE INTERACTION OF EMOTIONS AND FAIRNESS NORMS *
}

\author{
Ernesto Reuben ${ }^{\#}$ \\ e.reuben@uva.nl
}

\section{Frans van Winden ${ }^{\#}$ \\ F.A.A.M.vanWinden@uva.nl}

\begin{abstract}
This experimental study investigates how behavior changes after punishment for an unkind action. It also studies how fairness perceptions affect the reaction to punishment and whether this effect is consistent across repeated play and role experiences. A repeated version of the power-totake game is used. In this game, the proposer can make a claim on the resources of a responder. Then, the responder can destroy any part of her own resources. The focus is on how proposers adjust their behavior depending on their fairness perceptions, their experienced emotions, and their interaction with responders. We find that fairness plays an important role in the behavior of proposers. Specifically, deviations from a perceived fairness norm trigger feelings of shame and guilt, which induce proposers to lower their claims. However, we also find that the perceived fairness norm varies considerably between individuals. Therefore, it is not the case that proposers who considered they were acting fairly were particularly nice to responders. Our results also show that the different types of individuals predicted by models of social preferences, can be traced among the subjects that played the same role in both periods, but fail to describe the behavior of subjects who switched from one role to the other.
\end{abstract}

January 2005

\footnotetext{
* We would like to thank the participants of the International Meeting on Experimental and Behavioral Economics in Cordoba 2004 for their very useful comments.

\# CREED, Department of Economics, University of Amsterdam, Roetersstraat 11, 1018 WB Amsterdam, The Netherlands.
} 


\section{Introduction}

By now, it is a well-documented fact that individuals who participate in economic experiments are willing to spend money in order to punish people who have treated them unkindly. Emotions are often sited as the motivating factor behind this type of behavior (e.g. Fehr and Gächter, 2002). Recently, a number of researchers have begun to explicitly investigate the link between emotions and reciprocity. ${ }^{1}$ They explain an individual's decision to negatively reciprocate or not as the outcome of a tradeoff between an emotional urge to punish an unacceptable offer and the (more cognitive) reward of a monetary gain. However, all these studies concentrate on the motivations and behavior of the individuals who do the punishing.

An important goal of this paper is to investigate through an experiment how individuals who are punished behave and what motivates their behavior. Whereas emotions seem to play an important role in motivating individuals to punish others, it is not clear yet in which way (if at all) emotions affect the decisions of the punished. Another goal of this paper is to study how an individual's perception of fairness affects her reaction to punishment and whether this effect is consistent over time and across experiences with positions in a game.

For our study, we use a repeated version of the power-to-take game. In this game, the proposer (or take authority) can make a claim on the resources of a responder. Then, the responder can destroy any part (including nothing and everything) of her own resources. Hence, the power-to-take game approximates social environments characterized by appropriation, such as taxation, common agency or monopolistic selling (Bosman and van Winden, 2002). For illustration, one might think of a tax authority selecting an income tax rate, while a taxpayer can negatively affect the income tax base (at a cost to herself). In the experiment, this game was played for two consecutive periods, where some of the subjects kept their role of either proposer or responder while others switched roles.

An important part of the experimental design is the measurement of the emotions of proposers after they observed whether responders, by destroying their own income, punished them or not in the first period. This allows us to study how the proposers' emotional reaction (in the first period) affects their decision in the second period. It turns out that emotions play an important role in determining how proposers change their decision from one period to the next. Proposers that experienced negative reciprocity and felt high intensities of shame and

\footnotetext{
${ }^{1}$ See e.g. Bosman and van Winden (2002), Sanfey et al. (2003), Ben-Shakhar et al. (2004), Quervain et al. (2004), and Reuben and van Winden (2004).
} 
guilt lowered their claims, while proposers who experienced no negative reciprocity and felt

high intensities of regret increased their claims. Furthermore, we find that the experience of shame and guilt does not simply depend on the size of the proposer's claim but is associated with the proposer's perception of what is fair.

The experimental design also allows us to determine the extent to which fairness perceptions vary among the subjects. Current theories that incorporate a notion of fairness typically assume that people know what is fair or unfair. Although we find support for the idea that fairness matters, we do not find much support for the presence of a clear and stable fairness norm. For example, we find that, compared to subjects who experienced only the role of proposers, subjects who experienced both the role of proposer and responder thought that proposers were entitled to claim more money.

Finally, with our design we are able to observe how the same subjects behave when they are in the proposer role and when they are in the responder role. Most theories predict that subjects who are 'kind' as proposers will also be the ones that negatively reciprocate, in contrast to 'unkind' proposers who are predicted to be unwilling to bear the cost of reciprocity. Our findings are not in line with this prediction. In fact, in some cases we find the opposite result.

The paper is organized as follows. In Section 2 we address some related research. Section 3 presents the experimental design and the main predictions that can be derived from the theoretical literature. In Section 4 we describe the experimental procedures. Results are presented in Section 5, while Section 6 ends with a concluding discussion.

\section{Related Research}

Our work is related to three different areas of research. First, we hope to contribute to the growing literature on the economic significance of emotions and their role in decisionmaking. Second, our work is related to research focusing on proposer behavior in ultimatum games. Finally, this paper is related to studies concerned with how fairness norms affect individual behavior.

There is small but growing number of studies explicitly referring to emotions to explain behavior in the kind of game investigated in this paper. However, they all concentrate on the emotions and behavior of responders. By now, there is strong evidence suggesting that the destruction of income by responders is induced by anger-like emotions (such as anger, irritation, and contempt). An early paper exploring this issue is Pillutla and Murnighan (1996). Responders in an ultimatum game experiment were asked, after each of a series of 
offers, to answer the open-ended question "How do you feel?" Answers to the question were rated for expressions of the emotion of anger, and the rejection of offers was found to be related to this measure. Bosman and van Winden (2002) introduced the power-to-take game with the specific purpose of investigating in a controlled way the importance of emotions for reciprocity. They also had responders self-report on their feelings, but now concerning a list of different emotions and for a one-shot game. In addition, they asked for responders' expectations (regarding the take rate). Their results show that the destruction of income is related to the intensity of experienced anger-like emotions, which in turn is positively related to the actual take rate and negatively to the expected take rate (see also Bosman et al., 2004; Reuben and van Winden, 2004). Recently, evidence has been found of a biological substrate for the negative reciprocity exhibited by responders. Sanfey et al. (2003), using fMRI of ultimatum game players, find that 'unfair' offers elicited activity in brain areas related to both emotion and cognition, and heightened activity in an area related to emotions in case of rejection. In a similar study, Quervain et al. (2004) use a trust game with punishment opportunities to show that the effective punishment of norm violators produces activity in areas of the brain associated with the processing of rewards. Ben-Shakhar et al. (2004), using skin conductance as physiological measure of emotional arousal as well as self-reports, find that both self-reported anger and physiological arousal are related to destruction in the powerto-take game. Moreover, the self-reported measures of emotions appeared to be correlated with the physiological measures, which is reassuring for the use of self-reports in the study of reciprocity. With this paper, we take an important next step in this line of research by studying how emotions affect the decisions of proposers.

Even though there seem to be no studies exploring the role of emotions in proposer behavior, there is considerable research on proposer behavior in the ultimatum bargaining game. Space constraints allow only a quick overview of the main findings. ${ }^{2}$ Broadly speaking, proposers seem to be motivated by a combination of 'strategic' and 'non-strategic' behavior. Strategic behavior, in the restricted sense of going for the highest offer that will not be rejected, is clearly observed since proposers adjust their behavior depending on the likelihood of responders to reject an offer. For example, offers go down in cases where responders are less likely to reject, such as when the total size of the pie is unknown (see e.g. Camerer and Loewenstein, 1993; Straub and Murnighan, 1995; Rapoport et al., 1996), when there is competition among responders (Roth et al., 1991), or in the extreme case of a dictator

\footnotetext{
${ }^{2}$ For a good summary of the main results see Camerer (2003).
} 
game in which responders cannot reject at all (Forsythe et al., 1994). However, the fact that, even in completely anonymous dictator games there are positive offers seems to indicate that there is a degree of non-strategic (perhaps fairness-guided) behavior. Further evidence of non-strategic behavior is provided by Lin and Sunder (2002), who find that (given the responders' reactions) the proposers' offers are slightly higher than the optimal profitmaximizing offer. ${ }^{3}$ Moreover, if one thinks that the non-strategic behavior is due to fairness norms, there is growing evidence that these can be subject to self-serving biases (Knez and Camerer, 1995; Schmitt, 2004; Reuben and van Winden 2004). By analyzing whether and to what extent emotions play a role in proposer behavior, we hope to contribute to the tearing apart of such strategic and non-strategic factors in the decisions of proposers.

Finally, this study is related to research on fairness norms. Over the past decade, numerous authors have been studying behavior that cannot be explained with the standard economic model assuming self-regarding preferences. More importantly, some of the seemingly 'anomalous' behavior has been successfully modeled by theories that try to incorporate such norms into the utility functions of individuals. Different authors have used different notions of what constitutes fair and unfair behavior, which has fostered an extensive debate on which notion best describes the data of experiments. ${ }^{4}$ However, only a few researchers have explicitly asked for the fairness perceptions of individuals and, more importantly, analyzed how their fairness perceptions interact with other variables. Pillutla and Murninghan (1996) measure the fairness perceptions of responders and find that perceived unfairness is related to the rejection of offers. In contrast, more recent research by Reuben and van Winden (2004) indicates that, once the effect of the offered amount and the responder's expected offer are taken into account, the perceived unfairness of an offer has no longer a significant effect on destruction. Nonetheless, even though fairness perceptions might not be an important determinant when it comes to responder behavior, they might play a significant role when it comes to proposer behavior. In this paper, we investigate how and in what way fairness perceptions affect the decisions of proposers.

\footnotetext{
${ }^{3}$ See also Henrich et al. (2001) for clear evidence of such non-optimal offers in various non-western societies.

${ }^{4}$ Examples of different ways of modeling fairness include: equality (Fehr and Schmidt, 1999; Bolton and Ockenfels, 2000), a combination of efficiency and maximizing the welfare of the poorest individual (Charness and Rabin, 2002), and the midpoint between the best and the worst available alternatives (Rabin, 1993).
} 


\section{Experimental Design and Theoretical Predictions}

For our study, we use a repeated version of the power-to-take game. Subjects played the game for two periods. In each period one subject, who can be considered as the 'take authority' or proposer (with endowment $E_{\text {prop}}$ ), was matched with another subject, the responder (with endowment $E_{\text {resp }}$ ). The game consists of two stages. In the first stage, the randomly chosen proposer decides on the 'take rate' $t \in[0,1]$, which is the part of the responder's endowment after the second stage that will be transferred to the proposer. In the second stage, the responder decides to destroy a part $d$ of her own endowment $E_{\text {resp }}$, with $d \in$ $[0,1]$. For the proposer the payoff of the game equals her endowment plus the transfer from the responder, i.e. $E_{\text {prop }}+t(1-d) E_{\text {resp }}$, while the responder's payoff equals the part of her endowment that she does not destroy minus the amount transferred to the proposer, i.e. (1 $t)(1-d) E_{\text {resp. }}$. In order not to introduce too many behavioral issues at a time, in our experiment all endowments were equal $\left(E_{\text {resp }}=E_{\text {prop }}\right){ }^{5}$

In each of the two periods, subjects were randomly assigned to either the proposer's role or the responder's role. Consecutively, each proposer was randomly paired with a responder with a perfect-stranger matching protocol. Note that this eliminates any incentive to build up a reputation. In addition, this procedure produced a group of subjects that had the same role in both periods and another group that switched roles from one period to the other. Studying any behavioral differences between subjects that were proposers in both periods and subjects that were proposers only in the second period, allows us to test whether the role experienced in the first period affects behavior in the second.

During the experiment, we used self-reports as the research method for measuring emotions (Clore and Robinson, 2002), expectations, and fairness perceptions. Since we concentrate on proposer behavior, Figure 1 shows the precise order in which the proposers' decisions, emotions, expectations, and fairness perceptions were measured. Expectations were measured by asking subjects to indicate the most likely value for $d .{ }^{6}$ As in Bosman and van Winden (2002), subjects' emotions towards the other player were measured through selfreports after the subject observed what the other player did. Emotions were measured by

\footnotetext{
${ }^{5}$ The power-to-take game differs in 3 important ways from the well-known ultimatum game. First, in the powerto-take game each participant has an endowment. Second, in this game only the endowment of the responder is at stake. And third, the responder can destroy any amount of her endowment.

${ }^{6}$ We decided to measure expectations in this way since subjects might have difficulty in reporting a probability distribution of a continuous variable (over the interval [0,1]). Furthermore, in addition to the point estimate, we asked subjects to indicate on a 7-point scale how confident they were of their expectation.
} 
providing subjects with a list of fourteen emotion names and asking them to report on a 7point scale with what intensity they experienced each emotion. The scale ranged from "no intensity at all" (1) to "very intensely" (7). The list included the following emotions: pride, envy, anger, guilt, joy, shame, irritation, gratitude, surprise, contempt, disappointment, admiration, regret and sadness. A variety of emotions was included to avoid pushing subjects in a particular direction. We asked for the subjects' perceptions of the fair take rate, at the end, in a debriefing questionnaire.

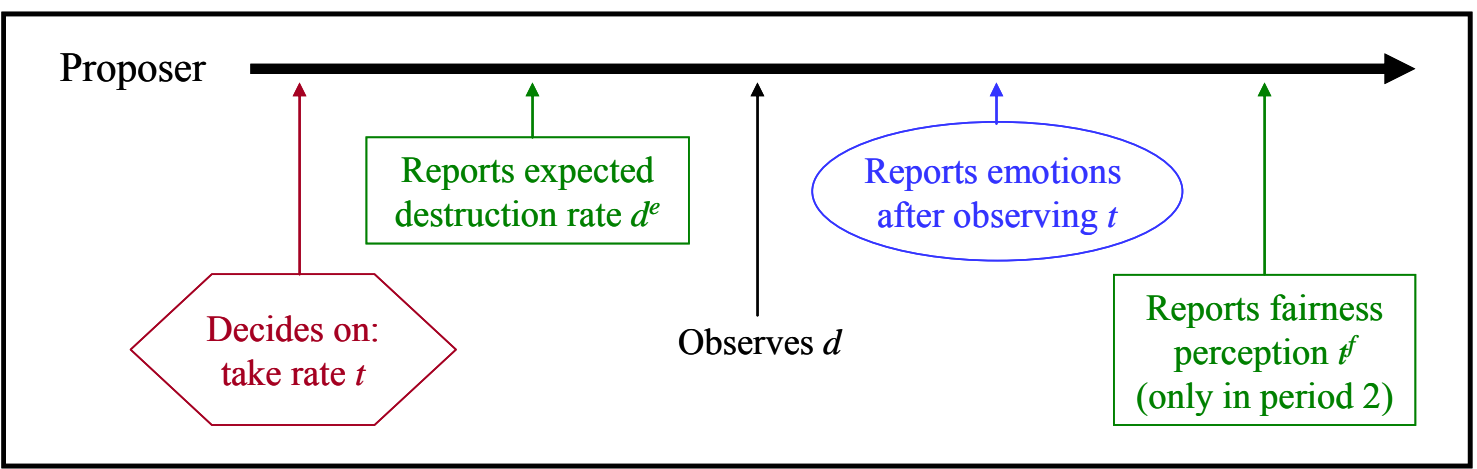

Figure 1: Sequence of events for proposers in each period

We now turn to the theoretical predictions of this game. Traditional economic theory, assuming own-payoff maximization, predicts that a proposer will choose to take essentially all of the responder's endowment and that the responder will not destroy any of it. However, previous work has proven that this is not the case. In the power-to-take game, responders consistently destroy some or all of their endowment when faced with high take rates, and proposers hardly ever choose to take all of the responders' endowment. In order to explain behavior in this and similar types of games researchers have constructed models that incorporate different kinds of fairness norms (see footnote 4) or emotions (Kirchsteiger, 1994; Levine, 1998). They do so by altering the utility function of individuals to include the monetary payoff and intentions of others. Some of these models predict remarkably well the behavior of responders. ${ }^{7}$ However, to the best of our knowledge, there are no theoretical models than can satisfactorily explain proposer behavior in the power-to-take game. ${ }^{8}$ It is not the aim of this paper to test the performance of individual models of social preferences.

\footnotetext{
${ }^{7}$ Specially: Fehr and Schmidt (1999), Bolton and Ockenfelds (2000), Falk and Fishbacher (2000), and Charness and Rabin (2002).

${ }^{8}$ All models, if calibrated to explain proposer behavior in the ultimatum game, predict that, in the power-to-take game, proposers will take considerably less from responders than they actually do. For a more thorough discussion on this finding, see Reuben and van Winden (2004).
} 
Instead, we wish to investigate whether proposer behavior provides support for some of the main assumptions in this literature.

Models of social preferences make various common assumptions. A first assumption is that the utility function of individuals has a 'material' part, which represents how much they value their own monetary payoff, and a 'non-material' part, which shows how much individuals value a combination of the distribution of monetary payoffs and the intentions of others. A second assumption is that individuals differ regarding the intensity with which they care about the non-material part of the utility function (relative to the material part). A third assumption is that, although individuals can differ with respect to their valuation of the nonmaterial part, everyone shares the same 'type' of preferences and this fact is common knowledge. To put it bluntly, everyone knows what is fair and what is unfair in every situation, but not everyone cares as much about it. Finally, a fourth assumption is that the value individuals attach to the non-material part of the utility function is the same irrespective of their position in the game and their past experiences. Although there is considerable evidence that gives support to the first two assumptions, the third and fourth assumptions have not been adequately tested. In this paper, we study whether there is support for the latter two assumptions. In order to do so, we must first describe the prediction of models of social preferences concerning the behavior of proposers in the repeated power-to-take game.

In the models of social preferences that accurately predict responder behavior (see footnote 7), proposers behave in roughly two distinct ways:

- First, there is a group of proposers who value the material part of the utility function relatively more than the non-material part. These proposers have a tendency to choose take rates that maximize their monetary payoff (given their beliefs of how responders behave). This usually leads them to choose relatively high take rates. Furthermore, since the choices of these proposers are restricted by the likelihood that responders will destroy, they will increase their take rate from period one to period two if their experience in period one makes them adjust downwards their general belief of the likelihood of destruction. Lastly, if these proposers were playing the role of a responder then they would be less likely to destroy their endowment than other individuals would. ${ }^{9}$

\footnotetext{
${ }^{9}$ This need not be the case in the model of Fehr and Schmidt (1999). In their model, responders destroy because they dislike disadvantageous inequality whereas proposers choose low take rates because they dislike advantageous inequality. Hence, proposers who choose high take rates will be less likely to destroy only if the
} 
- Second, there is another group of proposers who value the non-material part of the utility function relatively more than the material part. These proposers have a tendency to choose take rates that maximize their 'other-regarding' preferences. This usually means that these proposers are not maximizing their own monetary payoff (given their beliefs of how responders behave). This leads them to choose relatively low take rates. Furthermore, since normally the choices of these proposers will not be restricted by the likelihood that responders will destroy, they should not increase their take rate from period one to period two. Finally, if these proposers were playing the role of responders then they would be more likely to destroy their endowment than other individuals would.

In summary, models of social preferences predict that some proposers will be relative more interested in their material payoff and behave more 'strategically' and less in line with the fairness norm. The other proposers will be relatively more interested in their non-material payoff and behave less strategically and more in line with the fairness norm.

\section{Experimental Procedures}

The computerized experiment was run in October 2003 at the CREED laboratory of the University of Amsterdam. In total 92 subjects, almost all undergraduate students from the University of Amsterdam, participated in the experiment. About $41 \%$ of the subjects were women. Moreover, $41 \%$ were students of economics and the other $59 \%$ were students from various fields such as biology, political science, law, and psychology. Subjects were on average 22.21 years old. Subjects received a show-up fee of 2.5 euros, independent of their earnings in the experiment, and 10 euros as endowment in each of the two periods. On average, subjects were paid out 21.40 euros (approximately 24.90 US dollars). The whole experiment took about one and a half hours.

After arrival in the lab's reception room, each subject drew a card to be randomly assigned to a seat in the laboratory. Once everyone was seated, the instructions for the experiment were read aloud (a translation of the instructions is provided in Appendix 1). Subjects were told that the experiment consisted of two independent parts (each part being one of the periods in the two-period power-to-take game). We emphasized the fact that their choices in the first part of the experiment would not affect their earnings in the second part of the experiment. Furthermore, it was explained that the instructions for each part would be

aversion to both types of inequality is correlated. However, the accuracy of some of their predictions does rely on assuming such correlation (Fehr and Schmidt, 1999). 
given at the beginning of the respective part. After this, the one-shot power-to-take game was described in the instructions as the first part of the experiment. Thereafter, subjects had to answer a few exercises in order to check their understanding of the procedures. After these exercises the subjects were informed, by opening an envelope on their desk, which role (that of proposer or responder) they had been assigned in the first period of the game. The game was framed as neutral as possible, avoiding suggestive terms (like 'take rate'). Subsequently, the subjects played the first period of the power-to-take game via the computer. ${ }^{10}$ Once everyone finished, the instructions for the second part of the experiment were read. This simply consisted in informing subjects that they would play the same game once again. However, we did stress that they would be playing against a different person, and furthermore, that their role in the second part would be randomly determined and did not depend on what their role was in the first part. Subsequently, the subjects played the second period of the two-period power-to-take game.

\section{Results}

In this section, we present and analyze the decisions that were taken by proposers. Furthermore, we investigate whether fairness norms and the emotions reported by the subjects help explain the observed behavior. A summary of the individual data is provided in Appendix 2.

\section{Proposer behavior}

In general, proposers in our experiment behaved in a similar way to proposers in other powerto-take games. The average take rate, taken over both periods, was $58.8 \%$, and the median take rate was $60.0 \%$. See Table 1 for additional descriptive statistics. As in previous studies, we did not find that demographic variables, such as gender, age or area of study, had an effect on the chosen take rate.

To start, we analyze how proposers adjust their decision. Namely, how they change their take rate from one period to the next. In order to do so, we must concentrate on the subjects that had the role of proposers in both period one and period two. We will refer to this group of proposers as 'role-keepers'.

\footnotetext{
${ }^{10}$ The experiment was programmed and conducted with the software z-Tree (Fischbacher, 1999).
} 
Table 1: Descriptive statistics of role keepers

\begin{tabular}{|c|c|c|c|c|}
\hline \multirow[b]{2}{*}{ Average } & \multicolumn{2}{|c|}{ Proposer in both periods } & \multirow{2}{*}{$\begin{array}{c}\text { Proposer only } \\
\text { in period } 1 \\
\text { Period one }\end{array}$} & \multirow{2}{*}{$\begin{array}{c}\text { Proposer only } \\
\text { in period } 2 \\
\text { Period two }\end{array}$} \\
\hline & Period one & Period two & & \\
\hline Take Rate & $\begin{array}{l}56.5 \% \\
(21.8)\end{array}$ & $\begin{array}{l}59.0 \% \\
(20.0)\end{array}$ & $\begin{array}{c}56.3 \% \\
(16.5)\end{array}$ & $\begin{array}{l}63.7 \% \\
(18.2)\end{array}$ \\
\hline Destruction Rate & $\begin{array}{l}14.8 \% \\
(31.9)\end{array}$ & $\begin{array}{l}6.3 \% \\
(21.2) \\
\end{array}$ & $\begin{array}{l}6.9 \% \\
(18.4) \\
\end{array}$ & $\begin{array}{l}16.1 \% \\
(34.9)\end{array}$ \\
\hline $\begin{array}{c}\text { Expected Destruction } \\
\text { Rate }\end{array}$ & $\begin{array}{l}13.8 \% \\
(24.8)\end{array}$ & $\begin{array}{l}8.5 \% \\
(15.4)\end{array}$ & $\begin{array}{l}16.9 \% \\
(33.6)\end{array}$ & $\begin{array}{l}20.3 \% \\
(29.1)\end{array}$ \\
\hline $\begin{array}{c}\text { Frequency of } \\
\text { Destruction }\end{array}$ & $25.0 \%$ & $12.5 \%$ & $22.7 \%$ & $22.7 \%$ \\
\hline Fair Take Rate & & & $\begin{array}{l}43.9 \% \\
(23.7)\end{array}$ & $\begin{array}{l}40.9 \% \\
(19.8)\end{array}$ \\
\hline
\end{tabular}

Numbers between brackets are standard deviations.

On average, the take rate chosen by role-keepers was about the same in both periods (see Table 1). However, this hides considerable change at the individual level. Overall, $70.8 \%$ of role-keepers changed their take rate from period one to period two $(29.2 \%$ changed it by more than 10 percentage points). Of the role-keepers that changed their take rate, $29.4 \%$ decreased their take rate and the other $70.6 \%$ increased it. What is more, the role-keepers' decision to change the take rate was strongly affected by the behavior of the responder they faced in the first period. This leads us to our first result.

RESULT 1: Role-keepers who faced a responder who destroyed lowered their take rates whereas role-keepers who faced a responder who did not destroy increased their take rates.

Support: The average take rate of role-keepers who experienced destruction decreased from $67.5 \%$ to $61.7 \%$. The change in the take rate is different from zero with a Wilcoxon matchedpairs signed-rank test (WSR, $p<0.10$ ). ${ }^{11}$ Similarly, the average take rate of proposers who did not experience destruction increased from $52.8 \%$ to $58.1 \%$. The change in the take rate is significantly different from zero (WSR test, $p<0.05$ ).

\footnotetext{
${ }^{11}$ All tests in this paper are two-sided.
} 
However, experiencing destruction explains only a part of the role-keepers' decision to change the take rate. For instance, only $66.7 \%$ of the role-keepers who experienced no destruction increased their take rates. Similarly, only $50.0 \%$ of role-keepers who experienced destruction decreased their take rates. Furthermore, the amount destroyed did not seem to play an important role in determining by how much the role-keeper changes the take rate. For example, if we concentrate on the role-keepers that experienced some destruction, we find that: on average, role-keepers who experienced a destruction rate above the median decreased their take rate by 6.7 percentage points; likewise, on average role-keepers who experienced a destruction rate below the median decreased their take rate by a very similar 5.0 percentage points (we cannot reject equality using a Wilcoxon-Mann-Whitney (WMW) test, $p=0.82$ ).

The next step in our analysis is to try to explain why, when faced with a similar situation, some role-keepers decide to change their take rate and some do not. In order to do so, we divide role-keepers depending on whether or not they experienced destruction. Then, we compare the role-keepers who changed their take rate to the role-keepers who did not.

We start by looking at role-keepers who faced a responder who did not destroy. A possible reason why some of these role-keepers increased their take rates while others did not is that their expected destruction rates might have been different. It is reasonable to imagine that role-keepers who expected some destruction and observed no destruction would be more likely to increase their take rate than role-keepers who correctly anticipated no destruction. On average, this seems to be the case. However, the relationship is rather weak. Of the rolekeepers who correctly anticipated there would be no destruction, $63.6 \%$ increased their take rate. Likewise, of the role-keepers who expected some destruction (but experienced no destruction), $71.4 \%$ increased their take rates. There is not a significant difference between the two groups (WMW test, $p=0.74$ ).

Finally, contrary to the predictions of the models of social preferences, among rolekeepers who faced no destruction, role-keepers who increased their take rate after observing no destruction had not chosen higher take rates than role-keepers who kept or decreased their take rates. The former chose an average take rate of $50.0 \%$, and the later a take rate of $58.33 \%$ (the difference is not significant, RRO test, $p=0.19$ ). In order to find a possible explanation for why some role-keepers change their take rate and some do not, we now turn to the role-keepers' emotional response. We find the following result: 
RESULT 2: Role-keepers who increased their take rates after experiencing no destruction were role-keepers that reported high intensities of regret.

Support: WMW tests reveal that, among role-keepers who experienced no destruction, rolekeepers who increased their take rate reported higher intensities of regret $(p<0.01)$ than rolekeepers that did not change or decreased their take rate (2.58 vs. 1.00$)$.

Result 2 is quite intuitive. As one would expect, if a proposer reported feeling regret after observing that the responder did not destroy, this is because the proposer realized that he or she could have chosen a higher take rate. However, what is more interesting is that feeling regret does not seem to be related to the proposers' expectations. Normally, one would think that proposers that reported high intensities of regret were proposers that expected responders would destroy and then experienced no destruction. However, if we look at the role-keepers' expectations we find that this is not the case. Role-keepers who expected some destruction and experienced no destruction reported an average intensity of regret of 2.00. This is actually lower than the 2.09 average intensity of regret reported by the role-keepers who expected and experienced no destruction (the difference is not significant, WMW test, $p=$ 0.85). ${ }^{12}$ This result is not odd since there is a possible confounding effect that is hinted at by the models of social preferences. That is, that a group of proposers behave in a norm-abiding way and therefore, since they do not want to take more than the amount they are already taking, they do not feel regret when they realized they could have chosen a higher take rate. However, if this is indeed the case, then it means that norm-abiding proposers do not necessarily choose lower take rates than more strategic proposers. Role-keepers that increased their take rate after observing no destruction (i.e. behaved more strategically) had actually chosen lower take rates than role-keepers that did not change or decreased their take rate $(50.0 \%$ vs. $58.3 \%)$. However, there is no significant difference between the two groups (WMW test, $p=0.19$ ).

We now turn to role-keepers who faced a responder who did destroy some or all of his or her endowment. As in the previous case, it is possible that expectations could explain why

\footnotetext{
${ }^{12}$ Similarly, the change in the take rate for role-keepers who expected some destruction and faced no destruction was not significantly different from the change in the take rate of role-keepers who correctly anticipated no destruction (WMW test, $p=0.82$ ). This might suggest that expectations do not have a strong impact on a proposer's decision to change the take rate. However, since we do not have information on what proposers expected responders would do at take rates other than the chosen one, it would be premature to conclude that expectations do not play a role.
} 
some of these role-keepers reduced their take rate while others did not. Role-keepers who experienced a destruction rate that was higher than expected would be more likely to decrease their take rate than role-keepers who experienced a lower than expected destruction rate. Unfortunately, we cannot test whether this is true or not since none of role-keepers who experienced destruction expected a destruction rate that was higher than the one they confronted. Again, in order to get additional insights on the role-keepers' behavior, we analyze their emotional response. We find the following result.

RESULT 3: Role-keepers who decreased their take rates after experiencing some destruction were role-keepers that reported high intensities of shame.

Support: A WMW test shows that, among role-keepers who experienced some destruction, role-keepers who decreased their take rate reported higher intensities of shame $(p<0.05)$ than role-keepers that did not change their take rate (4.67 vs. 1.33$)$.

We also find the same qualitative pattern for the related emotion of guilt. However, in this case the difference is not significant (WMW test, $p=0.26$ ). Result 3 gives us an important insight into why proposers decrease their take rates from one period to the next. We explore this in the following paragraphs.

\section{Social norms}

The emotions of shame and guilt are triggered when an individual violates an internalized social norm. Furthermore, in the case of shame, the disapproval of others plays an important role on the intensity of the emotion (Tangney and Dearing, 2002). As we would expect, if the action of the responder makes a proposer feel bad by triggering these negative emotions, one would expect the proposer to adjust his or her behavior in order to feel better. Presumably, this leads proposers to lower their take rates. Naturally, this opens up the question of why some proposers feel shame and guilt while others do not. A casual look at the data reveals that, among role-keepers who observed destruction, shame and guilt are not triggered by high take rates: role-keepers with take rates above the median (on average, a take rate of $77.5 \%$ and an intensity of shame and guilt of 2.75 and 2.00) did not experience more shame and guilt than role-keepers with take rates below the median (on average, a take rate of $47.5 \%$ and an intensity of shame and guilt of 3.50 and 3.00). Thus, if shame and guilt are indeed triggered by deviations from a norm (presumably a fairness norm), it appears as though not all proposers consider choosing a high take rate as norm violation. On closer inspection, this 
seems to be the case. Once we take into account what proposers perceive to be the fair take rate $t^{f}$, we get a clear result.

RESULT 4: Role-keepers who chose take rates that they considered unfair experienced higher intensities of shame and guilt.

Support: If we divide the role-keepers into role-keepers that chose a take rate above what they considered fair $\left(t>t^{f}\right)$ and role-keepers that chose a take rate that equaled or was below what they considered fair $\left(t \leq t^{f}\right)$, we find that in both the first and the second period, rolekeepers who chose unfair take rates reported higher intensities of shame and guilt than rolekeepers who chose fair take rates (WMW tests, $p<0.05$ for shame and $p<0.10$ for guilt). Similarly, among the role-keepers who experienced destruction, role-keepers who chose unfair take rates reported higher intensities of shame than role-keepers who chose fair take rates (WMW test, $p<0.05){ }^{13}$

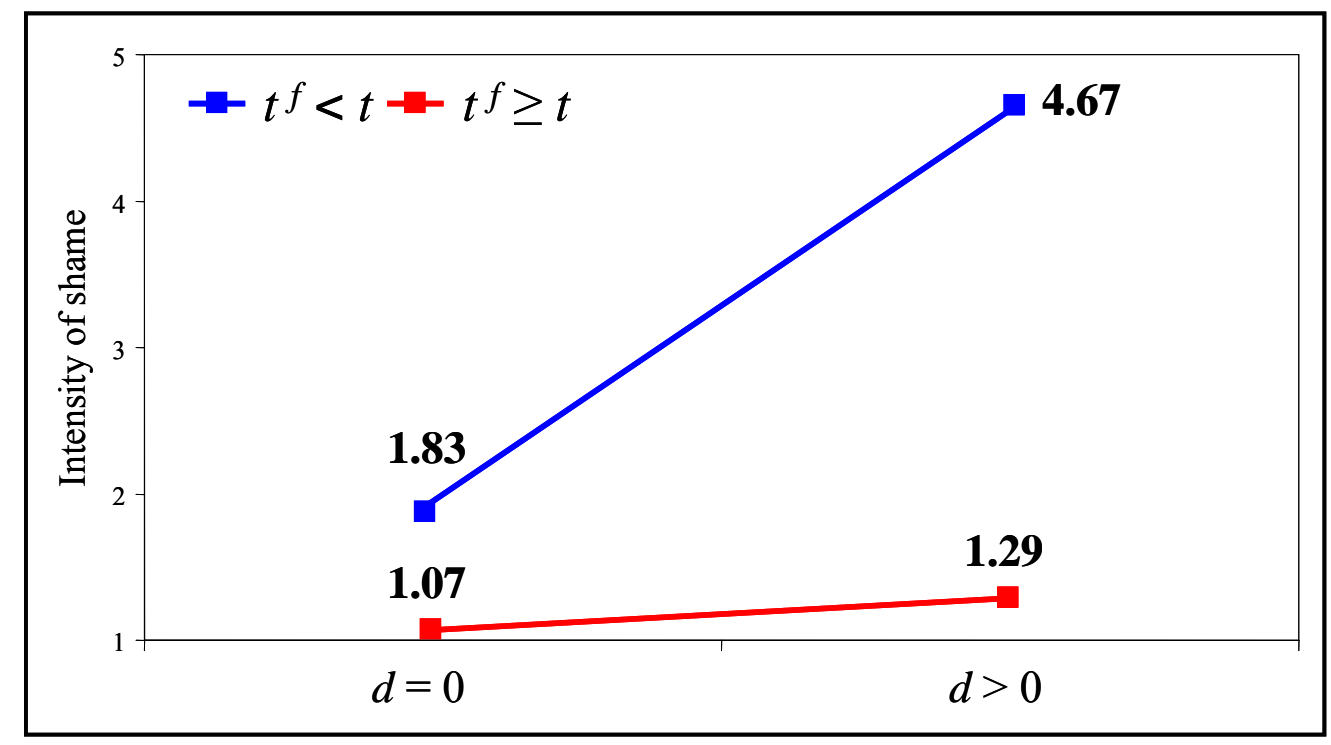

Figure 2: Role-keepers intensity of shame by destruction in period 1.

In summary, as Figure 2 illustrates, we seem to have a group of role-keepers who acknowledge they made an unfair choice and hence feel high intensities of shame (especially if they faced destruction) and guilt, and another group of role-keepers who believe they made a fair choice and therefore feel low intensities of both emotions (even after facing

\footnotetext{
${ }^{13}$ This part of the result is valid only for the first period. Unfortunately, in the second period all the role-keepers who experienced destruction happened to be role-keepers that considered they made an unfair offer. Hence, we cannot test whether they experienced more shame or not. Furthermore, we again find a similar pattern for guilt that nevertheless is not significant.
} 
destruction). Furthermore, as Result 3 shows, feeling high intensities of shame might be an important determinant on whether role-keepers lower their take rates. This would make rolekeepers in the first group more likely to lower their take rates than role-keepers in the second. ${ }^{14}$

Combining Results 3 and 4 we can arrive to the plausible conclusion that fairness perceptions, by triggering feelings of shame and perhaps guilt, have an impact on proposer behavior. However, what is perceived as fair varies from one person to another. In fact, there is more variation in fair take rates than in take rates (see the standard deviations in Table 1). Moreover, it is not necessarily true that, individuals that, in their opinion, are acting fairly are being considerably nicer to others. The main difference between role-keepers who chose a take rate they thought was fair and role-keepers who chose a take rate they thought was unfair is their fairness perception and not their chosen take rate. For example, in the first period, role-keepers that thought they were unfair chose a take rate that was 13.0 percentage points higher than role-keepers who thought they were fair, but at the same time, they reported a fair take rate that was 30.3 percentage points lower than role-keepers who thought they were fair.

We know from the literature on self-serving biases that groups of people in different circumstances can evaluate what is fair is different ways. With our results, we can add that even under the same circumstances there can be considerable variation in fairness perceptions. If fairness perceptions are indeed so diverse, studying whether past experiences affect the fairness perception of individuals becomes an important question. In order to answer it, we examine whether experiencing the role of a responder in the first period has an effect on the way proposers behave in the second period.

Again in Table 1 we present descriptive statistics for the group of proposers who had the responder role in the first period and the proposer role in the second. We will refer to this group of proposers as 'role-switchers'. Comparing the choices of role-keepers and roleswitchers in the second period, we note that role-switchers choose slightly higher take rates. However, the most striking difference between the two groups is actually in the fair take rates (see Table 1). This is stated in the following result.

\footnotetext{
${ }^{14}$ Result 3 refers only to role-keepers who faced destruction. However, we find a similar pattern for role-keepers who faced no destruction. Among these, role-keepers who reduced their take rates reported above average intensities of shame.
} 


\section{RESULT 5: Role-switchers reported higher fair take rates than role-keepers.}

Support: On average, role-switchers chose a fair take rate equal to $40.9 \%$ while role-keepers chose a fair take rate of $32.0 \%$ (the former is higher, WMW test, $p<0.10$ ).

It appears that being a responder in the first period has a noticeable effect on the proposers' fairness perceptions. However, we find the same effect on the responders' side. Subjects that had the responder role for both period one and two reported lower fair take rates than subjects that were first a proposer and then a responder $(28.8 \%$ vs. $43.9 \%$, WMW test, $p<0.10)$. Hence, it seems that experiencing both roles instead of just one is what produces an important effect on what is considered fair. ${ }^{15}$ More specifically, it appears that the shift in fair take rates is caused by more individuals stating it is fair to take $50.0 \%$ instead of $0.0 \%$ (see Figure 3 ).

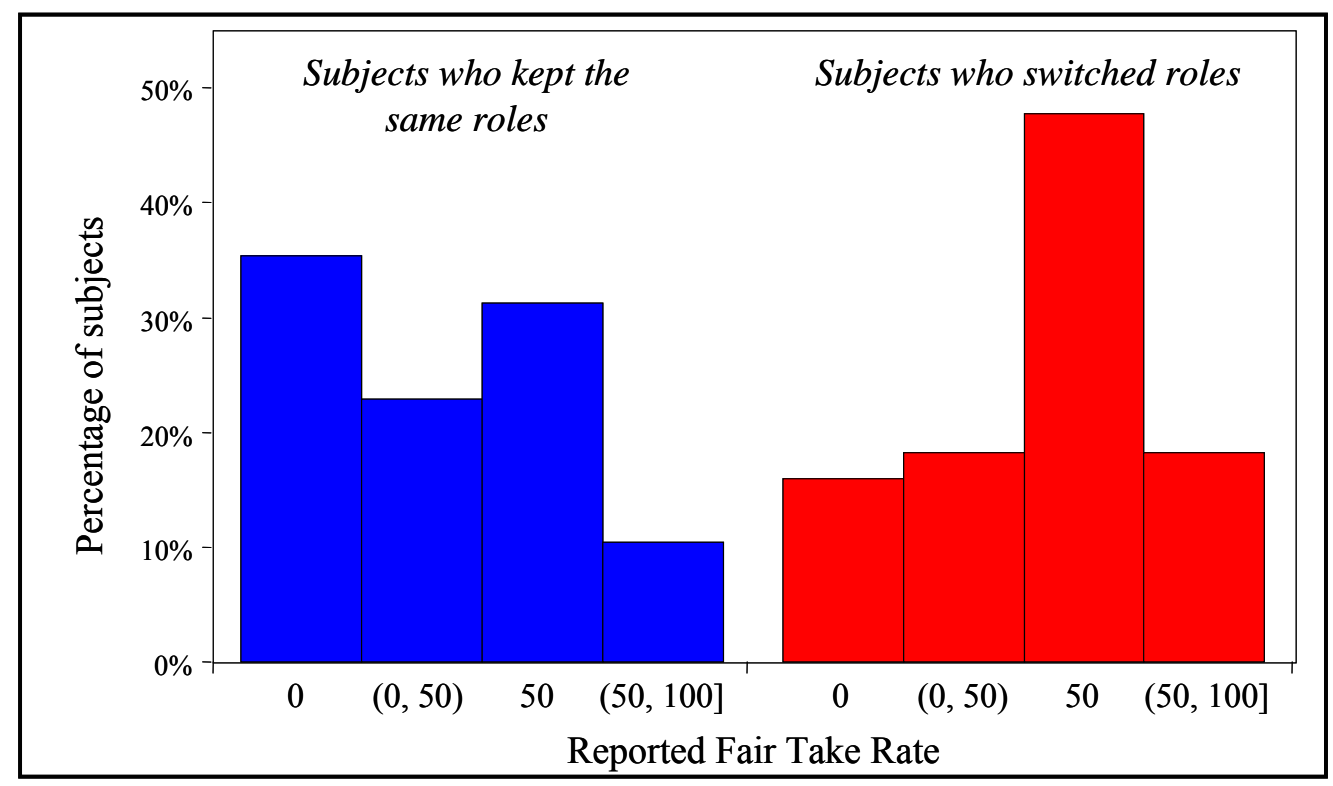

Figure 3: Histogram of fair take rates depending on whether the subjects switched roles or not.

The difference in fair take rates has a noticeable effect on the emotions of shame and guilt. As role-keepers, role-switchers who chose take rates that they considered unfair experienced higher intensities of shame and guilt than role-switchers who chose take rates they considered fair (WMW test, $p<0.10$ ). However, the higher fair take rates produce a lower proportion of role-switchers that think they made an unfair choice. Specifically, whereas $75.0 \%$ of role-

\footnotetext{
${ }^{15}$ Perhaps, experiencing both roles makes more salient the fact that there is mobility between positions in the game. This may induce a belief that everyone can be in an advantageous position at some point, and hence consider it acceptable for people to take advantage of those occasions.
} 
keepers considered they made an unfair choice, only $59.1 \%$ of role-switchers considered they did. Consequently, on average, role-switchers experienced lower intensities of shame and guilt than the role-keepers. If, as is true for role-keepers, high intensities of shame induce proposers to take less, one could suppose that role-switchers would be less inclined to decrease their already high take rates.

\section{Social preferences}

We now turn to see whether alternating roles has also an impact on individual behavior. As we have seen, alternating roles has a considerable impact on the fairness perceptions of subjects and consequently on their emotional reaction. However, on average there is not a significant effect on the actual choices of subjects. Role-keepers chose lower take rates than role-switchers, but this difference is not significant (WMW test, $p=0.76$ ). Similarly, on the responder side, responders that kept the same role destroyed less frequently than responders that were first a proposer (12.5\% vs. $22.7 \%)$. However, again the difference is not significant (WMW test, $p=0.37$ ). Nevertheless, we do find some interesting results once we look at how individuals choose across periods.

As we mentioned, models of social preferences predict that individuals should be more or less consistent across periods (since preferences are assumed to be constant). More specifically, role-keepers that chose high (low) take rates in the first period should, on average, choose high (low) take rates in the second period. Similarly, responders that chose high (low) destruction rates in the first period should, on average, choose high (low) destruction rates in the second period. When it comes to role-switchers, models of social preferences predict that subjects who, as responders, destroyed in the first period, should on average select low take rates in the second period. In the same way, subjects that, as proposers, decided on high take rates in the first period should on average destroy less in the second period. ${ }^{16}$ As it turns out, we find that these predictions are only consistent with subjects that did not switch roles.

RESULT 6: In line with models of social preferences, role-keepers who chose low take rates in the first period also chose low take rates in the second period.

Support: Role-keepers who chose a below-average take rate in the first period chose significantly lower take rates in the second period than role-keepers who chose an aboveaverage take rate $(48.3 \%$ vs. $69.6 \%$, WMW test, $p<0.01)$.

\footnotetext{
${ }^{16}$ See footnote 9.
} 
This result is consistent with models of social preferences. One could argue that role-keepers that consistently chose low take rates are revealing a preference for fair outcomes. After all, these role-keepers are foregoing money by their choices. On average, role-keepers that chose high take rates earned higher profits than role-keepers that chose low take rates (WMW test, $p<0.05)$. This is also true for subjects that were a responder in both periods. Among these responders, those who chose an above-average destruction rate in the first period also chose higher destruction rates in the second period (on average $21.7 \%$ vs. $1.1 \%$, WMW test, $p<$ 0.10). This is remarkable given that, in the second period, both groups of responders faced very similar take rates $(57.5 \%$ vs. $57.2 \%)$. It is evident that responders who destroyed earned lower profits than responders who did not destroy. Hence, this gives some support to the idea that some responders have preferences for punishing unfair behavior. We now turn to the subjects who switched roles and our next result.

RESULT 7: Contrary to models of social preferences, role-switchers who destroyed some of their income in the first period chose high take rates in the second period.

Support: Role-switchers that destroyed a positive amount in the first period (as responders) chose significantly higher take rates $(77.0 \%$ vs. $59.8 \%, p<0.05)$ than role switchers that did not destroy.

This result is in conflict with the predictions of the models of social preferences. Individuals that destroy a positive amount show, according to these models, that they value considerably the non-material part of their utility function. It follows that, in period two, these same individuals should choose low take rates. On the responders' side we find a similar, albeit weaker, result. Among subjects who switched from the proposer role to the responder role, subjects who chose above-average take rates in the first period chose a similar destruction rate in the second period than subjects who chose below-average take rates $(18.1 \%$ vs. $14.1 \%$ ). This difference is not significant (WMW test, $p=0.72$ ). Nevertheless, we do not find, as predicted, that subjects that chose high take rates as proposers also destroy less as responders. In the following section, we discuss how these findings question the viability of models of social preferences as they are now conceived and what are some of the promising ways of improving them. 


\section{Concluding discussion}

In this paper we have investigated how proposers in the power-to-take game adjust their behavior depending on their interaction with responders, their fairness perceptions, and experienced emotions. Our main results can be summarized by the following statements:

- Fairness considerations appear to play an important role in the behavior of proposers. Specifically, deviations from a perceived fairness norm trigger feelings of shame and guilt, which induce proposers to lower their take rates.

- The perceived fairness norm varies considerably between individuals. In fact, there is more variation in the perception of the fairness norm than variation in the behavior of the individuals.

- The different types of individuals predicted by models of social preferences can be traced among the subjects that played the same role in both periods, but fail to describe the behavior of subjects who switched from one role to the other.

Our results show that fairness norms, through the emotions of shame and guilt, play a significant role in the proposers' decision-making process. Since shame and guilt are emotions that are experienced when individuals think they have violated a social norm (Lazarus, 1991), our findings suggest that an internalized social norm influences proposers in this type of games. This is suggested by the observation that if responders destroy, they provoke high intensities of shame among proposers. This is not surprising since the emotion of shame is strongly associated with the perceived disapproval of others (Tangney and Dearing, 2002). As a consequence, the punishment of proposers becomes cheaper since destroying income not only reduces the income of the other but it also makes proposers feel bad. ${ }^{17}$ Furthermore, it highlights the importance for responders of being able to signal their displeasure. The bare existence of a fairness norm might not be enough to restrain the behavior of proposers.

Knowing that shame affects the decision-making process of proposers can help us improve our models in order to make predictions that are more accurate across different situations. ${ }^{18}$ For example, research on emotions tells us that people feel more shame and guilt

\footnotetext{
${ }^{17}$ It would also explain why simply making your displeasure known has a similar effect to monetary punishment in public goods settings (Masclet et al., 2003).

${ }^{18}$ At this point, the only model that incorporates both shame and guilt is Bowles and Gintis (2003).
} 
in situations in which others can clearly observe their actions and can show their disapproval (Tangney and Dearing, 2002). This would be consistent with proposers asking more in ultimatum games in which the amount to be divided in unknown. Uncertainty over the size of the pie prevents responders from clearly judging the actions of proposers. This might make proposers feel less shame. It would also be consistent with a lower proportion of proposers choosing the equal split in the dictator as opposed to the ultimatum game. ${ }^{19}$ Since, in dictator games responders cannot signal their displeasure, proposers are less exposed to feel high intensities of shame. In fact, the emotion of shame would also explain why proposers in dictator games take more as we increase the level of anonymity (as in double-blind experiments, Hoffman et al., 1994). Of course, for shame or guilt to have an effect in oneshot games, it must be the case that subjects are able to anticipate their emotional response. In this experiment, we cannot test whether this is true. However, recent work in Lazear et al. (2004) provides some support for this idea. If proposers make positive offers in dictator games in order to avoid feeling shame or guilt, then it is possible that, if given a choice, proposers would like to avoid being in the dictator game in the first place. Lazear et al. (2004) study precisely this situation and find that proposers who take the least when forced to play a dictator game are also the most willing to avoid playing. This is exactly what a model that incorporates individuals who anticipate feelings of shame and guilt would predict.

Although fairness norms appear to have an effect on proposer behavior, we also observe that the perception of what is fair varies substantially among proposers. Considering that the concept of fairness is vague in many situations, it is not surprising that not all proposers agree on what is fair in the power-to-take game. This means that, even if proposers want to be fair when playing the game, they first have to figure out what fairness means in that specific context. Clearly, this opens the door to self-serving biases. However, we find that the disagreement among proposers on what is fair is far greater than the disagreement between proposers and responders. ${ }^{20}$ This raises the question whether we are indeed observing the effect of a social norm, which is necessarily linked to what other people think, or rather a

\footnotetext{
${ }^{19}$ This difference between dictator and ultimatum games cannot be explained by most models of social preferences (the exception being Levine, 1998). In these models, a proposer who chooses the equal split in the ultimatum game does so because that allocation provides her with the highest utility and not because of the possibility that responder might reject. Hence, in the dictator game, these proposers should also choose an equal split.

${ }^{20} \mathrm{We}$ do not find significant evidence of a self-serving bias. On average, subjects who were only proposers considered that the fair take rate was $32.0 \%$ whereas subjects who were only responders considered the fair take rate to be $28.8 \%$. The difference is not significant (WMW test, $p=0.92$ ).
} 
personal value. Further research is needed to differentiate between the two possibilities. However, we do feel that the prominence of an emotion like shame points in the direction of there being a social norm that is simply perceived differently by different people. In this case, in order to act optimally, individuals must not only learn how others behave but also the appropriate interpretation of fairness. As individuals interact, they can adjust their beliefs of what is fair. What turns out to be fair in the long run could then vary considerably depending on the experiences of those involved in the process. Suggestive in this respect is the observed shift in fair take rate beliefs between role-keepers and role-switchers.

This brings us to our final set of results. That is, individuals that are willing to punish others for treating them badly are not necessarily willing to treat others nicely. So far, the literature on social preferences views negative and positive reciprocity as two sides of the same coin. However, this assumption has not been tested exhaustively. Evidence from public good games with punishment does suggest that individuals who cooperate are indeed also the individuals who punish others for not cooperating (Fehr and Gächter, 2000). However, it is not clear whether this relation will survive when individuals are playing in different roles across different games. Our results seem to indicate that people are indeed consistent in their behavior when playing the same role (as is also the case in public good experiments). Yet, they do not behave as consistently when changing from one role to another. ${ }^{21}$

Our research seems to indicate that the situation of a responder is actually quite different from the situation of a proposer. Whereas the decisions of proposers seem to be influenced by fairness norms and emotions such as shame and guilt, responders seem to react in a different way. Previous research has demonstrated that responders destroy because they are angry (e.g. see Pillutla and Murnighan, 1996; Bosman and van Winden, 2002). Furthermore, their anger seems to be triggered by the difference between how much the proposer offered and how much they expected the proposer to offer (van Winden, 2001). Their fairness perception seems to play only an indirect role by influencing the responders' expectations (Reuben and van Winden, 2004). To conclude, it appears that the motivations behind the behavior of responders are different from the motivations behind the behavior of proposers. More generally, modeling kind and unkind behavior as two separate phenomena might be a fruitful line of research. ${ }^{22}$

\footnotetext{
${ }^{21}$ Coricelli (2002) finds similar results where, depending on the sequence that games are played, individuals sometimes exhibit negative reciprocity but no positive reciprocity and sometimes the reverse.

${ }^{22}$ See also Loewenstein et al. (1989) for further discussion on the qualitative difference between the reactions of individuals depending on whether they have a positive of negative relationship with others.
} 
Finally, we wish to emphasize that measuring the emotional reaction of subjects can help us understand what is motivating them to make certain decisions. In this case, we identify shame, and possibly guilt, as an important motivation for proposers to reduce their take rates. We do not argue that it is always necessary to know the precise emotional and cognitive processes by which subjects arrive at a decision. However, whenever we have a situation in which our theories are not providing us with good predictions, a better understanding of the motivations of individuals can help improve the modeling of behavior. 


\section{Appendix 1 - Instructions}

These are the instructions used in the experiment.

Instructions (translation from Dutch)

Welcome to this experiment on decision-making. In this experiment, you can earn money. How much you earn depends on your decisions and the decisions of other participants. In addition to your earnings, you will also receive a show-up fee of 2.50 euros.

The experiment consists of two parts, Part I and Part II. In each part, you can earn money. Note that, the two parts of the experiment are completely independent of each other. In other words, what you decide in Part I will not affect your earnings in Part II.

At the end of Part II, you will be paid privately in cash the total amount you have earned plus your show-up fee.

During the experiment, you are not allowed to communicate with other participants. If you have a question, please raise your hand. We will then come to you to answer it.

We will begin now with the instructions for Part I of the experiment. You will receive the instructions for Part II after Part I has been completed.

During the experiment, you will be asked to fill in a few questionnaires. The answers you provide in these questionnaires are completely anonymous. They will not be revealed to anyone neither during the experiment nor thereafter. Furthermore, your answers will not affect your earnings during the experiment.

If you have any questions now, please raise your hand. If you do not have any questions, please click on 'Ready'.

Instructions - Part I

In Part I of the experiment each of you will be paired to another participant. This other participant will be chosen at random from among the other participants in the experiment.

In this part of the experiment, some of you will be positioned to move first and some of you will be positioned to move second. Participants moving first will be referred to with the letter $A$, while participants moving second will be referred to with the letter $B$.

Before the experiment started each desk was assigned either an A or a B. Therefore, by randomly picking a yellow card (in the reception room), each participant was randomly assigned to a position in the experiment. The letter that you were assigned is written inside the envelope located on your desk. You will be asked to open the envelope once we finish reading the instructions. The corresponding letter will also appear on the top-right part of the computer screen. 
Note that each A is paired with a B. Moreover, since the pairing is random, the identities of both participants will remain anonymous.

At the beginning of Part I, all participants (both A and B) receive 10 euros. We will refer to this amount as the endowment of each participant.

Part I consists of two phases. In phase one, only A must make a decision. Similarly, in phase two, only B must make a decision. Hence, every participant makes only one decision. We will now describe the decision of each $\mathrm{A}$ and $\mathrm{B}$.

\section{Phase 1: A chooses a percentage}

In this phase, A must choose a percentage and type it into the corresponding field in the computer screen. This percentage determines how much of the endowment of B after phase two will be transferred to $A$. The percentage chosen must be an integer between 0 and 100 (inclusive).

If you wish to make any calculations, you can use the calculator located on your desk.

Once you are satisfied with your decision, you have to confirm it by clicking on the button 'Ready'. Note that all decisions are final, once you have clicked on 'Ready' you cannot change your choice. Once A has completed phase 1, phase 2 begins.

Phase 2: B chooses a percentage

At the beginning of this phase, B is informed of the percentage chosen by A.

Then, B must also choose a percentage and type it into the corresponding field in the computer screen. This percentage determines what percentage of B's endowment (of the 10 euros) will be destroyed. Again, the percentage must be an integer between 0 and 100 inclusive.

Note that, the transfer from B to A will be based only on the endowment of B that is not destroyed. Again, if you wish to make any calculations, you can use the calculator located on your desk.

Once you are satisfied with your decision, you have to confirm it by clicking on the button 'Ready'. Note that all decisions are final, once you have clicked on 'Ready' you cannot change your choice. Once B has made his or her decision phase 2 ends.

\section{Earnings}

After phase 2, all participants will be informed of the amount of money they have earned. You will also be informed of the amount of money earned by the participant you are paired with. 


\section{Example of how to calculate you earnings}

We will now give an example for the purpose of illustration. Remember that both A and B have an endowment of 10 euros. Suppose that in phase 1, A decides that $30 \%$ of the endowment of B will be transferred to him or her (participant A). In phase 2, B can destroy part or everything of his or her 10 euros. Suppose B decides to destroy $0 \%$ percent of his or her endowment. The transfer from $\mathrm{B}$ to $\mathrm{A}$ is then equal to 3 euros ( $30 \%$ of 10 euros). The earnings of $\mathrm{B}$ are equal to 7 euros (namely, the endowment of 10 euros minus the transfer of 3 euros). The earnings of $\mathrm{A}$ are equal to 13 euros (namely, the endowment of 10 euros plus the transfer of 3 euros).

Now suppose that in this example B decides to destroy $50 \%$ of his or her endowment. In this case, the transfer to $\mathrm{A}$ is only 1.50 euros (namely, $30 \%$ of the remaining endowment after phase 2, that is $30 \%$ of 5 euros). The earnings of A are equal to 11.50 euros (namely, the endowment of 10 euros plus the transfer of 1.5 euros). The earnings of B are equal to 3.50 euro (namely, $50 \%$ of the endowment of 10 euros minus the transfer of 1.50 euros).

In summary

In this part of the experiment, each $\mathrm{A}$ is randomly and anonymously paired with a $\mathrm{B}$, and each participant receives an endowment of 10 euros. There are two phases. In phase 1, A decides on a percentage that indicates how much of the endowment of B after phase 2 will be transferred to $\mathrm{A}$. In phase $2, \mathrm{~B}$ decides what percentage of his or her endowment will be destroyed.

Next, we will ask you to answer a few questions in order to familiarize you with the calculation of your earnings. If you have any questions now, please raise your hand. If you do not have any questions, please click on 'Ready'. Note that once you click on 'Ready' you will not be able to go back to the instructions.

Instructions - Part II

In Part II of the experiment, you will face a situation that is similar to Part I. Each participant will receive an additional 10 euros (which we will call again your endowment). Please note that Part I and Part II are independent so that earnings in Part I will not be affected by your earnings in Part II.

Two differences with respect to Part I

There are two differences between Part I and Part II. One is that your position (A or B) might not be the same, and the other is the participant you are paired with.

Again, before the experiment started, each desk was assigned either an A or a B for Part II as well as Part I. Therefore, by randomly assigning the cards; each participant was also 
randomly assigned to a position in Part II. The position to which you were assigned in Part II will be displayed in the computer screen. Note that, whichever position you are assigned does not depend on the position you were assigned in Part I.

Furthermore, in Part II, the participant you will be paired with will not be the same participant with whom you were paired in Part I of the experiment. Your new pair will be chosen at random by the computer from among the other participants. In other words, you might be paired with anyone except the participant with whom you were paired in Part I.

The rest of the experiment is as in Part I.

In summary

In this part of the experiment, each participant receives an endowment of 10 euros. There are two phases. In phase 1 A decides on a percentage that indicates how much of B's endowment (of Part II) after phase 2 will be transferred to A. In phase 2, B decides what percentage of his or her endowment (of Part II) will be destroyed.

If you have any questions now, please raise your hand. If you do not have any questions, please click on 'Ready'. Note that once you click on 'Ready' you will not be able to go back to the instructions. 


\section{Appendix 2 - Summary of individual data}

Table 2: Take and destruction rates for subjects who kept the same role

\begin{tabular}{|c|c|c|c|c|c|c|}
\hline \multirow[b]{2}{*}{ Subject \# } & \multicolumn{3}{|c|}{ Period one } & \multicolumn{3}{|c|}{ Period two } \\
\hline & Position & $t$ & $d$ & Position & $t$ & $d$ \\
\hline 1 & $\mathrm{P}$ & 0 & 0 & $\mathrm{P}$ & 0 & 0 \\
\hline 2 & $\mathrm{P}$ & 25 & 0 & $\mathrm{P}$ & 30 & 0 \\
\hline 3 & $\mathrm{P}$ & 35 & 0 & $\mathrm{P}$ & 50 & 0 \\
\hline 4 & $\mathrm{P}$ & 40 & 0 & $\mathrm{P}$ & 60 & 0 \\
\hline 5 & $\mathrm{P}$ & 40 & 0 & $\mathrm{P}$ & 60 & 0 \\
\hline 6 & $\mathrm{P}$ & 45 & 0 & $\mathrm{P}$ & 55 & 0 \\
\hline 7 & $\mathrm{P}$ & 45 & 10 & $\mathrm{P}$ & 40 & 20 \\
\hline 8 & $\mathrm{P}$ & 50 & 75 & $\mathrm{P}$ & 50 & 0 \\
\hline 9 & $\mathrm{P}$ & 50 & 0 & $\mathrm{P}$ & 70 & 0 \\
\hline 10 & $\mathrm{P}$ & 50 & 0 & $\mathrm{P}$ & 65 & 0 \\
\hline 11 & $\mathrm{P}$ & 50 & 0 & $\mathrm{P}$ & 40 & 0 \\
\hline 12 & $\mathrm{P}$ & 55 & 0 & $\mathrm{P}$ & 60 & 0 \\
\hline 13 & $\mathrm{P}$ & 60 & 50 & $\mathrm{P}$ & 50 & 0 \\
\hline 14 & $\mathrm{P}$ & 60 & 20 & $\mathrm{P}$ & 60 & 0 \\
\hline 15 & $\mathrm{P}$ & 60 & 0 & $\mathrm{P}$ & 65 & 0 \\
\hline 16 & $\mathrm{P}$ & 60 & 0 & $\mathrm{P}$ & 65 & 0 \\
\hline 17 & $\mathrm{P}$ & 60 & 0 & $\mathrm{P}$ & 60 & 0 \\
\hline 18 & $\mathrm{P}$ & 65 & 0 & $\mathrm{P}$ & 70 & 0 \\
\hline 19 & $\mathrm{P}$ & 75 & 0 & $\mathrm{P}$ & 50 & 30 \\
\hline 20 & $\mathrm{P}$ & 75 & 0 & $\mathrm{P}$ & 80 & 0 \\
\hline 21 & $\mathrm{P}$ & 75 & 0 & $\mathrm{P}$ & 75 & 0 \\
\hline 22 & $\mathrm{P}$ & 90 & 0 & $\mathrm{P}$ & 90 & 100 \\
\hline 23 & $\mathrm{P}$ & 90 & 100 & $\mathrm{P}$ & 70 & 0 \\
\hline 24 & $\mathrm{P}$ & 100 & 100 & $\mathrm{P}$ & 100 & 0 \\
\hline 25 & $\mathrm{R}$ & 0 & 0 & $\mathrm{R}$ & 60 & 0 \\
\hline 26 & $\mathrm{R}$ & 25 & 0 & $\mathrm{R}$ & 60 & 0 \\
\hline 27 & $\mathrm{R}$ & 35 & 0 & $\mathrm{R}$ & 65 & 0 \\
\hline 28 & $\mathrm{R}$ & 40 & 0 & $\mathrm{R}$ & 30 & 0 \\
\hline 29 & $\mathrm{R}$ & 40 & 0 & $\mathrm{R}$ & 50 & 0 \\
\hline 30 & $\mathrm{R}$ & 45 & 0 & $\mathrm{R}$ & 60 & 0 \\
\hline 31 & $\mathrm{R}$ & 45 & 10 & $\mathrm{R}$ & 40 & 0 \\
\hline 32 & $\mathrm{R}$ & 50 & 75 & $\mathrm{R}$ & 60 & 0 \\
\hline 33 & $\mathrm{R}$ & 50 & 0 & $\mathrm{R}$ & 65 & 0 \\
\hline 34 & $\mathrm{R}$ & 50 & 0 & $\mathrm{R}$ & 70 & 0 \\
\hline 35 & $\mathrm{R}$ & 50 & 0 & $\mathrm{R}$ & 75 & 0 \\
\hline 36 & $\mathrm{R}$ & 55 & 0 & $\mathrm{R}$ & 70 & 0 \\
\hline 37 & $\mathrm{R}$ & 60 & 50 & $\mathrm{R}$ & 50 & 30 \\
\hline 38 & $\mathrm{R}$ & 60 & 20 & $\mathrm{R}$ & 50 & 0 \\
\hline 39 & $\mathrm{R}$ & 60 & 0 & $\mathrm{R}$ & 49 & 0 \\
\hline 40 & $\mathrm{R}$ & 60 & 0 & $\mathrm{R}$ & 70 & 0 \\
\hline 41 & $\mathrm{R}$ & 60 & 0 & $\mathrm{R}$ & 40 & 20 \\
\hline 42 & $\mathrm{R}$ & 65 & 0 & $\mathrm{R}$ & 80 & 0 \\
\hline 43 & $\mathrm{R}$ & 75 & 0 & $\mathrm{R}$ & 50 & 0 \\
\hline 44 & $\mathrm{R}$ & 75 & 0 & $\mathrm{R}$ & 65 & 0 \\
\hline 45 & $\mathrm{R}$ & 75 & 0 & $\mathrm{R}$ & 0 & 0 \\
\hline 46 & $\mathrm{R}$ & 90 & 0 & $\mathrm{R}$ & 70 & 0 \\
\hline 47 & $\mathrm{R}$ & 90 & 100 & $\mathrm{R}$ & 90 & 100 \\
\hline 48 & $\mathrm{R}$ & 100 & 100 & $\mathrm{R}$ & 55 & 0 \\
\hline
\end{tabular}


Table 3: Take and destruction rates for subjects who switched roles

\begin{tabular}{|c|c|c|c|c|c|c|}
\hline \multirow[b]{2}{*}{ Subject \# } & \multicolumn{3}{|c|}{ Period one } & \multicolumn{3}{|c|}{ Period two } \\
\hline & Position & $t$ & $d$ & Position & $t$ & $d$ \\
\hline 1 & $P$ & 35 & 0 & $\mathrm{R}$ & 65 & 0 \\
\hline 2 & $\mathrm{P}$ & 35 & 0 & $\mathrm{R}$ & 100 & 100 \\
\hline 3 & $P$ & 40 & 0 & $\mathrm{R}$ & 50 & 0 \\
\hline 4 & $\mathrm{P}$ & 40 & 10 & $\mathrm{R}$ & 40 & 0 \\
\hline 5 & $\mathrm{P}$ & 40 & 0 & $\mathrm{R}$ & 65 & 30 \\
\hline 6 & $P$ & 40 & 0 & $\mathrm{R}$ & 50 & 0 \\
\hline 7 & $\mathrm{P}$ & 45 & 0 & $\mathrm{R}$ & 70 & 0 \\
\hline 8 & $\mathrm{P}$ & 50 & 0 & $\mathrm{R}$ & 50 & 0 \\
\hline 9 & $\mathrm{P}$ & 50 & 0 & $\mathrm{R}$ & 60 & 0 \\
\hline 10 & $\mathrm{P}$ & 50 & 0 & $\mathrm{R}$ & 65 & 0 \\
\hline 11 & $P$ & 50 & 0 & $\mathrm{R}$ & 60 & 25 \\
\hline 12 & $\mathrm{P}$ & 54 & 0 & $\mathrm{R}$ & 100 & 0 \\
\hline 13 & $\mathrm{P}$ & 55 & 5 & $\mathrm{R}$ & 100 & 100 \\
\hline 14 & P & 60 & 0 & $\mathrm{R}$ & 40 & 0 \\
\hline 15 & $\mathrm{P}$ & 60 & 0 & $\mathrm{R}$ & 45 & 0 \\
\hline 16 & $\mathrm{P}$ & 65 & 10 & $\mathrm{R}$ & 50 & 0 \\
\hline 17 & $P$ & 70 & 66 & $\mathrm{R}$ & 83 & 99 \\
\hline 18 & $\mathrm{P}$ & 72 & 0 & $\mathrm{R}$ & 60 & 0 \\
\hline 19 & $\mathrm{P}$ & 75 & 0 & $\mathrm{R}$ & 85 & 0 \\
\hline 20 & $\mathrm{P}$ & 75 & 0 & $\mathrm{R}$ & 49 & 0 \\
\hline 21 & $\mathrm{P}$ & 80 & 0 & $\mathrm{R}$ & 65 & 0 \\
\hline 22 & $P$ & 97 & 60 & $\mathrm{R}$ & 90 & 0 \\
\hline 23 & $\mathrm{R}$ & 35 & 0 & $\mathrm{P}$ & 65 & 0 \\
\hline 24 & $\mathrm{R}$ & 35 & 0 & $\mathrm{P}$ & 100 & 100 \\
\hline 25 & $\mathrm{R}$ & 40 & 0 & $P$ & 85 & 0 \\
\hline 26 & $\mathrm{R}$ & 40 & 10 & $\mathrm{P}$ & 90 & 0 \\
\hline 27 & $\mathrm{R}$ & 40 & 0 & $\mathrm{P}$ & 40 & 0 \\
\hline 28 & $\mathrm{R}$ & 40 & 0 & $P$ & 50 & 0 \\
\hline 29 & $\mathrm{R}$ & 45 & 0 & $\mathrm{P}$ & 40 & 0 \\
\hline 30 & $\mathrm{R}$ & 50 & 0 & $\mathrm{P}$ & 45 & 0 \\
\hline 31 & $\mathrm{R}$ & 50 & 0 & $P$ & 49 & 0 \\
\hline 32 & $\mathrm{R}$ & 50 & 0 & $\mathrm{P}$ & 49 & 0 \\
\hline 33 & $\mathrm{R}$ & 50 & 0 & $P$ & 50 & 0 \\
\hline 34 & $\mathrm{R}$ & 54 & 0 & $\mathrm{P}$ & 65 & 0 \\
\hline 35 & $\mathrm{R}$ & 55 & 5 & P & 60 & 25 \\
\hline 36 & $\mathrm{R}$ & 60 & 0 & $\mathrm{P}$ & 50 & 0 \\
\hline 37 & $\mathrm{R}$ & 60 & 0 & $P$ & 50 & 0 \\
\hline 38 & $\mathrm{R}$ & 65 & 10 & $\mathrm{P}$ & 100 & 100 \\
\hline 39 & $\mathrm{R}$ & 70 & 66 & $\mathrm{P}$ & 65 & 0 \\
\hline 40 & $\mathrm{R}$ & 72 & 0 & $\mathrm{P}$ & 83 & 99 \\
\hline 41 & $\mathrm{R}$ & 75 & 0 & $\mathrm{P}$ & 70 & 0 \\
\hline 42 & $\mathrm{R}$ & 75 & 0 & $P$ & 60 & 0 \\
\hline 43 & $\mathrm{R}$ & 80 & 0 & $\mathrm{P}$ & 65 & 30 \\
\hline 44 & $\mathrm{R}$ & 97 & 60 & $P$ & 70 & 0 \\
\hline
\end{tabular}

Where: $t=$ take rate, $d=$ destruction rate, $\mathrm{P}=$ proposer, and $\mathrm{R}=$ responder. 
Table 4: Mean emotional intensity of proposers

\begin{tabular}{|c|c|c|c|c|}
\hline \multirow[b]{2}{*}{ Emotion } & \multicolumn{2}{|c|}{ Proposer in both periods } & \multirow{2}{*}{$\begin{array}{c}\begin{array}{c}\text { Proposer only } \\
\text { in period } 1\end{array} \\
\text { Period one }\end{array}$} & \multirow{2}{*}{$\begin{array}{c}\begin{array}{c}\text { Proposer only } \\
\text { in period } 2\end{array} \\
\text { Period two }\end{array}$} \\
\hline & Period one & Period two & & \\
\hline admiration & $3.1(2.1)$ & $3.4(2.1)$ & $2.5(1.8)$ & $3.0(2.2)$ \\
\hline anger & $1.9(2.0)$ & $1.5(1.2)$ & $1.6(1.4)$ & $1.9(1.8)$ \\
\hline contempt & $1.5(1.2)$ & $1.5(1.1)$ & $1.9(1.5)$ & $1.9(1.2)$ \\
\hline disappointment & $2.1(1.9)$ & $1.6(1.5)$ & $1.9(1.6)$ & $2.1(1.8)$ \\
\hline envy & $1.6(1.3)$ & $1.3(0.8)$ & $1.3(0.8)$ & $2.0(1.4)$ \\
\hline gratitude & $4.5(2.0)$ & $4.8(1.9)$ & $3.6(2.1)$ & $3.6(2.2)$ \\
\hline guilt & $2.0(1.1)$ & $2.7(1.6)$ & $2.1(1.7)$ & $2.0(1.6)$ \\
\hline irritation & $2.0(1.8)$ & $1.6(1.4)$ & $2.0(1.8)$ & $2.4(2.0)$ \\
\hline joy & $4.5(1.6)$ & $4.7(1.9)$ & $4.5(1.7)$ & $4.1(2.1)$ \\
\hline pride & $3.8(1.3)$ & $4.2(1.9)$ & $3.8(1.7)$ & $3.8(2.2)$ \\
\hline regret & $2.3(1.5)$ & $2.3(1.8)$ & $2.0(1.7)$ & $2.0(1.7)$ \\
\hline sadness & $1.5(1.4)$ & $1.5(1.2)$ & $1.4(1.2)$ & $1.7(1.4)$ \\
\hline shame & $2.0(1.4)$ & $2.2(1.3)$ & $1.7(1.4)$ & $2.1(1.4)$ \\
\hline surprise & $3.7(2.1)$ & $4.0(1.7)$ & $3.1(2.0)$ & $2.9(2.0)$ \\
\hline
\end{tabular}

Numbers between brackets are standard deviations. 


\section{References}

Ben-Shakhar, G., G. Bornstein, A. Hopfensitz, and F. van Winden (2004). Reciprocity and emotions: Arousal, self-reports, and expectations. Working paper. University of Amsterdam.

Bolton, G. and A. Ockenfels (2000). A theory of equity, reciprocity, and competition. American Economic Review 90: 166-193.

Bosman, R., and F. van Winden (2002). Emotional hazard in a power-to-take game experiment. The Economic Journal 112: 147-169.

Bosman, R., M. Sutter, and F. van Winden (2004). On the impact of real effort and emotions in power-to-take experiments. Journal of Economic Psychology, forthcoming.

Bowles, S. and H. Gintis (2003). Prosocial emotions. Working Paper \#02-07-028. Santa Fe Institute.

Camerer, C. (2003). Behavioral Game Theory. New Jersey: Princeton University Press.

Camerer, C. and G. Loewenstein (1993). Information, fairness, and efficiency in bargaining. In Mellers B. and J. Baron (Eds.) Psychological Perspectives on Justice: Theory and Applications. Cambridge: Cambridge University Press.

Charness, G. and M. Rabin (2002). Understanding social preferences with simple tests. The Quarterly Journal of Economics 117: 817-869.

Clore, G.L. and M.D. Robinson (2002). Belief and feeling: Evidence for an accessibility model of emotional self-report. Psychological Bulletin 128: 934-960.

Coricelli, G. (2002). Sequence matters: An experimental study of the effects of experiencing positive and negative reciprocity. Working paper. University of Siena.

Falk, A. and U. Fischbacher (2000). A theory of reciprocity. Working paper No. 6. Institute for Empirical Research in Economics, University of Zürich.

Fehr, E. and S. Gächter (2000). Cooperation and punishment in public goods experiments. American Economic Review 90: 980-994.

Fehr, E. and S. Gächter (2002). Altruistic punishment in humans. Nature 415: 137-140.

Fehr, E. and K. Schmidt (1999). A Theory of fairness, competition and cooperation. The Quarterly Journal of Economics 114: 817-868.

Fischbacher U. (1999). Zurich toolbox for readymade economic experiments, experimenter's manual. Working Paper No. 21. Institute for Empirical Research in Economics, University of Zürich. 
Forsythe, R., J.L. Horowitz, N.E. Savin, and M. Sefton (1994). Fairness in simple bargaining experiments. Games and Economic Behavior 6: 347-369.

Henrich, J., R. Boyd, S. Bowles, C. Camerer, E. Fehr, H. Gintis, and R. McElreath (2001). In search of homo economicus: Behavioral experiments in 15 small-scale societies. American Economic Review 91: 73-78.

Kirchsteiger, G. (1994). The role of envy in ultimatum games. Journal of Economic Behavior and Organization 25: 373-389.

Knez, M. and C.F. Camerer (1995). Outside options and social comparison in a three-player ultimatum game experiments. Games and Economic Behavior 10: 65-94.

Lazarus, R.S. (1991). Emotion and Adaptation. New York: Oxford University Press.

Lazear, E.P., U. Malmendier, and R.A. Weber (2004). Sorting in experiments. Working paper. Stanford University.

Levine, D. (1998). Modeling altruism and spitefulness in experiments. Review of Economic Dynamics 1: 593-622.

Lin, H. and S. Sunder (2002). Using experimental data to model bargaining behavior in ultimatum games. In Zwick R. and A. Rapoport (Eds.) Experimental Business Research. Dordrecht: Kluwer.

Loewenstein, G., L. Thompson, and M. Bazerman (1989). Social utility and decision making in interpersonal contexts. Journal of Personality and Social Psychology 57: 426-441.

Masclet, D., C. Noussair, S. Tucker, and M.C. Villeval (2003). Monetary and non-monetary punishment in the voluntary contributions mechanism. American Economic Review 93: 366-380.

Pillutla, M.M. and J.K. Murnighan (1996). Unfairness, anger, and spite: Emotional rejections of ultimatum offers. Organizational Behavior and Human Decision Processes 68: 208224.

Quervain, D.J.F., U. Fischbacher, V. Treyer, M. Schellhammer, U. Schnyder, A. Buck, and E. Fehr (2004). The neural basis of altruistic punishment. Science 305: 1254-1258.

Rabin, M. (1993). Incorporating fairness into game theory and economics. American Economic Review 83: 1281-1302.

Rapoport, A., J.A. Sundali, and R.E. Potter (1996). Ultimatums in two-person bargaining with one-sided uncertainty: Offer games. International Journal of Game Theory 25: 475494.

Reuben, E. and F. van Winden (2004). Reciprocity and emotions when reciprocators know each other. Discussion paper 04-098/1. Tinbergen Institute. 
Roth, A.E., V. Prasnikar, M. Okuno-Fujiware, and S. Zamir (1991). Bargaining and market behavior in Jerusalem, Ljubljana, Pittsburgh and Tokyo: An experimental study.

American Economic Review 81: 1068-1095.

Sanfey, A.G., J.K. Rilling, J.A. Aronson, L.E. Nystrom, and J.D. Cohen (2003). The Neural Basis of Economic Decision-Making in the Ultimatum Game. Science 300: 1755-1758.

Schmitt, P. (2004). On perceptions of fairness: The role of valuations, outside options, and information in ultimatum bargaining games. Experimental Economics 7: 49-73.

Straub, P. and K. Murnighan (1995). An experimental investigation of ultimatum games: Information, fairness, expectations, and lowest acceptable offers. Journal of Economic Behavior and Organization, 27: 345-364.

Tangney, J. P. and R. L. Dearing (2002). Shame and Guilt. New York: Guilford. van Winden, F. (2001). Emotional hazard exemplified by taxation-induced anger. KYKLOS 54: 491-506. 